\section{OP0330-HPR 'THE BEST THING WE HAVE IS EACH OTHER' - A QUALITATIVE DYADIC APPROACH TO EXPLORE SUPPORT IN EVERYDAY LIFE BETWEEN PERSONS WITH RA AND THEIR SIGNIFICANT OTHERS}

M. Bergström ${ }^{1}$, Å. Larsson Ranada ${ }^{1}$, A. Sverker ${ }^{1,2}$, I. Thyberg ${ }^{3,4}$, M. Bjork ${ }^{1,4}$. ${ }^{1}$ Linköping University, Department of Health, Medicine and Caring Sciences, Norrköping, Sweden; ${ }^{2}$ Region Östergötland, Department of Rehabilitation Medicine, Linköping, Sweden; ${ }^{3}$ Linköping University, Department of Biomedical and Clinical Sciences, Linköping, Sweden; ${ }^{4}$ Region Östergötland, Department of Rheumatology, Linköping, Sweden

Background: Participation in everyday life and the relationships between persons with rheumatoid arthritis (RA) and their significant others are often affected by the disease. Usually, both parts need to adapt to new roles [1]. However, the dyadic interaction between them in everyday life is yet to be understood on a deeper level. Objectives: To explore I) How dyads consisting of persons with RA and their significant others comprehend support and participation in everyday life, and II) how the dyadic interaction can influence their experience of participation in everyday life. Methods: In-depth individual interviews were conducted both with the persons with RA 12-13 years after diagnosis and inclusion in the Swedish multicenter project TIRA-2 [2], and with their significant others as defined by the persons with RA. Demographic data and the Valued Life Activity Scale (VLA-swe) [3] was reported by the persons with RA. To avoid bias, the persons with RA and their significant others were interviewed by different researches. Data from the interviews were transcribed verbatim and content analysis with a dyadic approach was undertaken [4]. The process of coding and categorizing was discussed between the researchers. The study was approved by the Regional Ethics Committee at Linköping University (Dnr. 2018/158-31), all participants gave their written consent. Results: Three women and two men with RA and five significant others, all represented by spouses, participated $(\mathrm{N}=10)$. The age of the persons with $\mathrm{RA}$ ranged from 34 to 67 years and a majority experienced difficulties in $\geq 12$ valued life activities. Three categories were revealed: 1) $A$ strong willpower affecting the dyadic relationship, meaning that the understanding within the dyads was that the persons with RA were not so keen to share status, which was mentioned in connection to tenacity and expectations. 2) Being a support to each other, referring to the mutual understanding within the couples that there was a constant exchange of support, forming a basis for participation in everyday life. However, disagreement was expressed concerning an unequal amount of support. 3) The dyads' potential issues with awareness, addressing the difficulty in fully comprehending the impact of the diagnosis. The couples mentioned an unwillingness from the person with RA to share information, and the significant other viewing comments as complaining. This type of miscommunication was interpreted as a potential negative effect on participation in everyday life.

Conclusion: A constant exchange of support within the dyads was evident. However, the dyadic relationships were often affected by the willpower of the persons with RA to be independent in everyday life. In addition, the dyads faced the concern of fully understanding the diagnosis. The results indicate further needs for interventions for both the persons with RA as well as the significant others, in order to boost the dyadic interaction, and thereby facilitate optimal participation in everyday life of persons with RA.

References:

[1] Brignon M, Vioulac C, Boujut E et al. (2019) Patients and relatives coping with inflammatory arthritis: care teamwork. Health Expect 2019;00:1-11

[2] Thyberg I, Dahlström Ö, Björk M, et al. (2017) Hand pains in women and men in early rheumatoid arthritis, a one year follow-up after diagnosis. The Swedish TIRA project. Disabil Rehabil 2017;39(3):291-300

[3] Björk M, Thyberg M, Valtersson, E et al. (2016) Validation and internal consistency of the Swedish version of the Valued Life Activities scale. Clin Rehabil 2016;30(12):1211-1219

[4] Eiskovits Z, Koren C (2010) Approaches to and outcomes of dyadic interview analysis. Qual Health Res 2010;20(12):1642-55

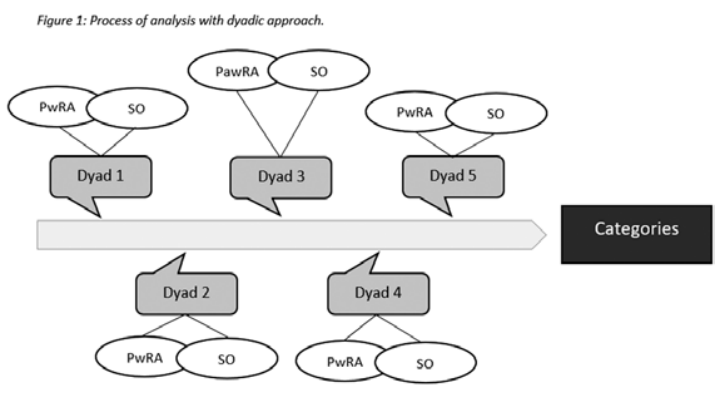

PwRA: Person with RA. so: Significant other
Disclosure of Interests: None declared

DOI: 10.1136/annrheumdis-2020-eular.4255

\section{OP0331-HPR BARRIERS TO SHARED DECISION-MAKING WITH WOMEN OF REPRODUCTIVE AGE AFFECTED BY CHRONIC INFLAMMATORY DISEASES}

S. Murray ${ }^{1}$, R. Fischer-Betz ${ }^{2}$, M. Augustyniak ${ }^{1}$, J. Murase ${ }^{3}$, C. Nelson-Piercy ${ }^{4,5}$, I. Vlaev ${ }^{6}$, C. Ecoffet ${ }^{7}$, M. Peniuta ${ }^{1}$, D. Jenkins ${ }^{7} .{ }^{1}$ AXDEV Group Inc., Brossard, Canada; ${ }^{2}$ Heinrich-Heine-University Hospital, Düsseldorf, Germany; ${ }^{3}$ University of California, San Francisco, United States of America; ${ }^{4}$ Imperial College Healthcare NHS Trust, London, United Kingdom; ${ }^{5}$ Guy's and St.Thomas' Hospitals Trust, London, United Kingdom; ${ }^{6}$ University of Warwick, Coventry, United Kingdom; ${ }^{7}$ UCB BioPharma SRL, Brussels, Belgium

Background: Previous research has indicated that women with a chronic inflammatory disease (CID) are likely to discontinue treatment during pregnancy. [1] Reasons for this are complex, including sub-optimal integration of shared decision-making (SDM) into practice.

Objectives: The purpose of this study was to assess: 1) physicians' competencies in risk assessment, treatment and management of women of reproductive age (WoRA) with a CID, and 2) clinical gaps, barriers and challenges to SDM with these patients.

Methods: A mixed-methods needs assessment was conducted. [2] Participants included rheumatologists and dermatologists practicing in Germany, United Kingdom, or United States, with at least three years of experience. Exposure to patients diagnosed with rheumatoid arthritis, psoriatic arthritis, axial spondyloarthritis or psoriasis was required. A first phase involved collection and thematic analysis of data from semi-structured interviews to identify main challenge areas. The second phase consisted of online surveys to validate and quantify identified challenges, gaps and barriers. Chi-square and Kruskal Wallis $\mathrm{H}$ statistical tests were performed to assess differences by specialty, country and gender. Qualitative and quantitative findings were triangulated with insight from experts in medical education and relevant behavioural and clinical fields. [3] The present summary reports data pertaining to rheumatologists only.

Results: A total of 24 interviews and 173 surveys were completed with rheumatologists. Depending on the country and specific item, $22 \%$ to $64 \%$ reported having sub-optimal knowledge of treatment options, patient education aids, and strategies to assess treatment adherence among WoRA with a CID (see figure 1). In addition, $36 \%$ reported having sub-optimal knowledge of methods to achieve SDM Unplanned pregnancies were reported as a barrier to prescribing biologics to WoRA with a CID. Yet, $61 \%$ of rheumatologists reported having sub-optimal skills discussing contraceptive methods with patients. In addition, $41 \%$ reported having sub-optimal skills adjusting treatment according to changes in pregnancy status or child-bearing aspirations. Few differences in clinical gaps were observed by gender. Notably, a greater proportion of male rheumatologists reported having sub-optimal skills approaching WoRA in a way that makes them feel comfortable discussing their health concerns, compared to female rheumatologists $(52 \%$ vs. $30 \%, p=0.046)$. This skill gap was identified as a contributing barrier to SDM with these patients.

Conclusion: This study identified multiple challenges, gaps and barriers relevant to rheumatologists that prevent optimal SDM, risk assessment, treatment and management of WoRA with CID. Findings may be used to develop medical education and continuous professional development interventions for target learners. References:

[1] Tsao NW, Lynd LD, Sadatsafavi M, Hanley G and De Vera MA. Patterns of biologics utilization and discontinuation before and during pregnancy in women with autoimmune diseases: a population-based cohort study.Arthritis Care Res., 2018;70(7):979-986.

[2] Creswell JW, Klassen AC, Plano Clark VL, Smith KC. Best practices for mixed methods research in the health sciences, 2nd Ed. Bethesda: $\mathrm{NIH}$ 2018:541-545,

[3] Turner SF, Cardinal LB, Burton RM, A triangulation-based framework and roadmap. Organ. Res. Methods, 2017;20(2): 243-26.

Acknowledgments: This research was financially supported with educational funds from UCB BioPharma SRL. The authors thank T. Kellner for his contribution. Disclosure of Interests: Suzanne Murray: None declared, Rebecca Fischer-Betz Consultant of: UCB, Speakers bureau: Abbvie, Amgen, Biogen, BMS, Celgene, Chugai, GSK, Janssen, Lilly, Medac, MSD, Novartis, Roche, UCB, Pfizer., Monica Augustyniak: None declared, Jenny Murase Consultant of: I have led advisory boards for UCB., Speakers bureau: I have done non-branded talks on psoriasis management in women for UCB., Catherine Nelson-Piercy Consultant of: I have received consultancy fees from UCB, Speakers bureau: I have received fees for speaking from UCB., Ivo Vlaev Consultant of: For UCB., Speakers bureau: For UCB, Pfizer, Novartis and boehringer Ingelheim., Cecile Ecoffet Shareholder of: UCB, Employee of: UCB, Morgan Peniuta: None declared, Dean Jenkins Employee of: UCB DOI: 10.1136/annrheumdis-2020-eular.449 